\title{
Retention of vertically migrating suprabenthic mysids in fjords
}

\author{
Stein Kaartvedt \\ Department of Marine Biology, University of Bergen, N-5065 Blomsterdalen, Norway
}

\begin{abstract}
Horizontal and vertical pelagic distribution patterns at night of the vertically migrating suprabenthic mysids Boreomysis megalops, Lophogaster typicus, Leptomysis gracilis and Schistomysis ornata were studied in Masfjorden, western Norway. Horizontal distributions were highly patchy, and reflected known localities of daytime bottom habitats. Little evidence of horizontal dispersal was found in spite of extensive upward migration at night $(>100 \mathrm{~m}$ away from bottom). Fjords seem to offer suitable habitats for vertically migrating mysids through relative low advective forcing, thereby facilitating population maintenance within a locality. However, current data indicate that population. maintenance is not possible if mysids drift passively during the pelagic phase. It is suggested that dispersal is reduced by mysid behaviour.
\end{abstract}

\section{INTRODUCTION}

Suprabenthos, or hyperbenthos, are functionally tied to the bottom, but with varying regularity swim above the sediment. Mysids are common members of the suprabenthos during the day, but may leave the bottom and undertake vertical migrations at night (e.g Brunel 1979, Kaartvedt 1985). By living in close association with the sediment, vulnerability to advection is reduced since current velocity decreases exponentially in the bottom meter (Hollister et al, 1974, Fosså 1985, Jahn \& Lavenberg 1986). As mysids lack planktonic larval stages, diel vertical migration has been considered beneficial as a means of enhancing dispersal (Tattersall \& Tattersall 1951). On the other hand, individuals caught by currents may be transferred to locations which are not suitable in terms of, for example, sediment type or depth, and advective loss could conceivably prohibit population maintenance. Shallowliving mysids exhibit some degree of permanence on their home site by means of numerous behavioural adaptations (Robertson et al. 1968, Clutter 1969, Wittman 1977, Wooldridge \& Erasmus 1980, McFarland \& Kotchian 1982, Hahn \& Itzkowitz 1986, Orsi 1986). However, the question of advection as a constraint for population maintenance in deep-living mysids performing diel vertical migrations has generally not been addressed.

If vertically migrating mysids are passively displaced by currents, the following aspects of their migration patterns are key questions: What proportion of the population takes part in vertical migration? How far up in the water column do the mysids swim (currents may be stronger in upper layers)? How much time is spent in advective layers? How regular is vertical migration (i.e. do the mysids migrate every night or only on some nights)?

If passive drift is prevailing, populations may persist in low advective locations only. Alternatively, the mysids may be able to maintain horizontal position during vertical migration to assure re-entry to the appropriate habitat following the pelagic phase, or they may adjust migration patterns during unfavorable currents (e.g. omit migration).

The present paper presents results on the nocturnal pelagic distribution of suprabenthic mysids in Masfjorden, Norway. Both vertical and horizontal distribution patterns were determined. Also the current system of the fjord was evaluated. By comtining these data, the degree of displacement, or conversely the degree of retention, of suprabenthic mysids is discussed.

\section{STUDY AREA}

Masfjorden is $20 \mathrm{~km}$ long, and situated north of Bergen, western Norway (Fig. 1). The fjord borders on Fensfjorden, through which it is connected to outer coastal waters. The water masses of Masfjorden consist of a brackish layer (upper few metres), intermediate 


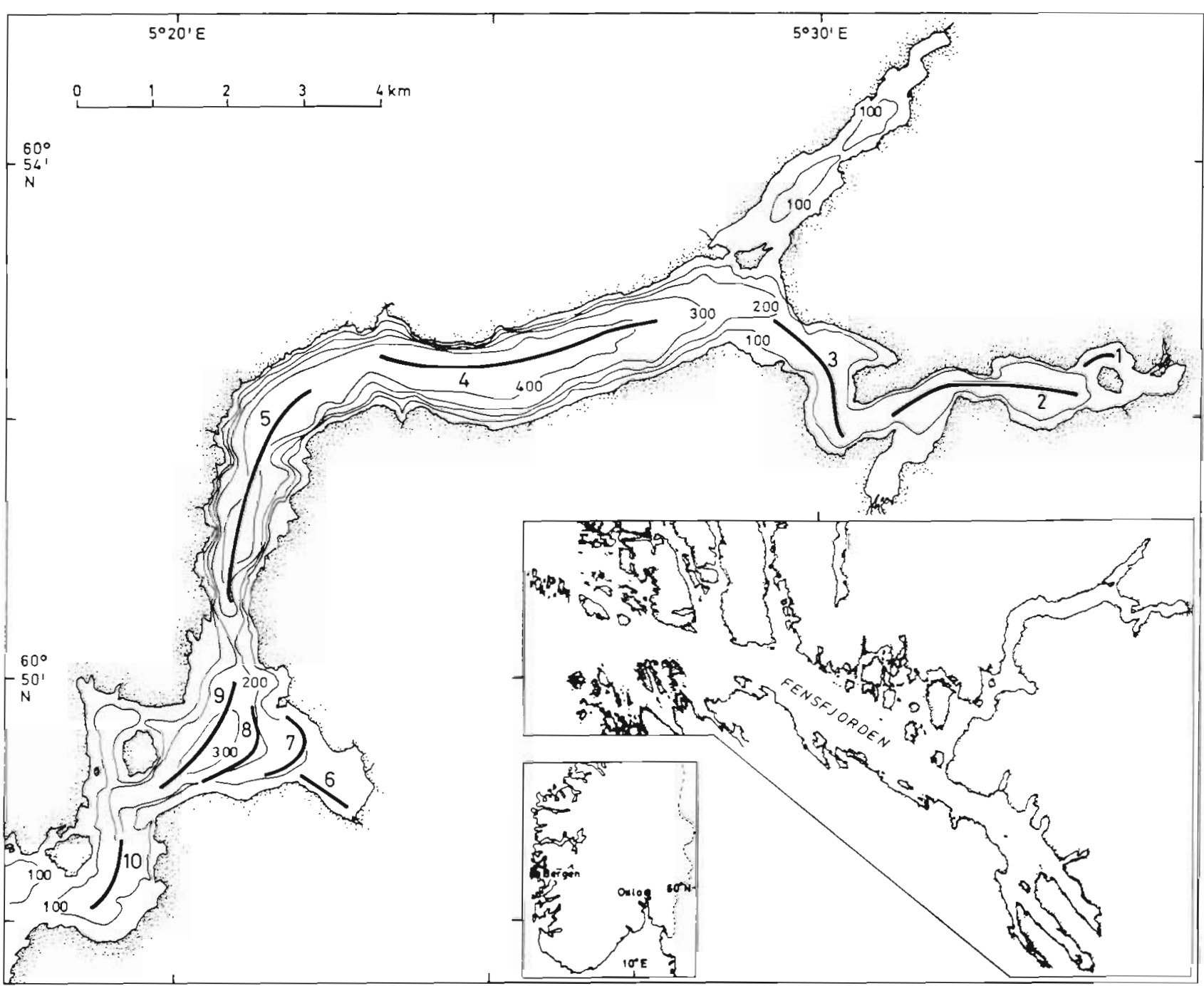

Fig. 1. Masfjorden with bottom contours (m). Tracks of the IKMT tows at Stns 1 to 10 are indicated

water between the brackish water and the sill depth (75 $\mathrm{m}$ ) and basin water below the sill depth. The tidal amplitude is 0.5 to $1 \mathrm{~m}$. At the head of the inner, southern branch of the fjord, there is a hydroelectric power plant, supplying the fjord with freshwater at a maximum rate of $50 \mathrm{~m}^{3} \mathrm{~s}^{-1}$. This runoff causes a short residence time of surface waters (Sætre 1974). Residual currents in the intermediate layer are governed by winds on the coast, or sudden intrusions of water from the Skagerrak (southeast of Norway). The direction of the circulation reverses with reversing wind fields, and changes in the coastal water rapidly propagate into Masfjorden. During a 5 d period in June 1985, residual currents across the sill were 6 to $10 \mathrm{~cm} \mathrm{~s}^{-1}$ (Aksnes et al. 1989), giving an estimated residence time of water above sill depth of $12 \mathrm{~d}$. In October 1985, residual currents were weaker ( $\mathrm{ca} 4 \mathrm{~cm} \mathrm{~s}^{-1}$ ), but on this occasion tidal currents were prominent with maximum velocities of ca 15 to $20 \mathrm{~cm} \mathrm{~s}^{-1}$ (Aksnes et al. 1989). Exchange of the basin water may not occur over several years. Between 1976 and 1980, one total and one partial renewal of the basin water was indicated (J. Aure pers. comm.). During this period, the oxygen level in the deep water varied between 3.7 and $5.5 \mathrm{ml} \mathrm{O}_{2} \mathrm{l}^{-1}$.

\section{MATERIAL AND METHODS}

Samples were collected during cruises with RV 'Håkon Mosby' in October and December 1986, and in January 1987. Pelagic sampling was mainly performed by an Isaac-Kidd Midwater Trawl (IKMT) with a mouth aperture of $2 / 3 \mathrm{~m}^{2}$ and a $500 \mu \mathrm{m}$ net. The net was towed in oblique hauls at a speed of 2 knots. The sampling depth was measured by a Benthos Time-Depth Recorder. During the sampling in January 1987, the timedepth recorder did not function correctly, and depths on this occasion were estimated by wire length/depth 
relationships established during the previous sampling. The volume of water filtered was estimated by multiplying the trawled distance by the net aperture.

The purpose of the October survey was to establish the horizontal pelagic distribution at night and a rough vertical distribution of the vertically migrating mysids. A total of 57 IKMT samples were collected throughout the fjord. Details are given in Table 1. The sampling in December 1986 and January 1987 was designed to obtain more information on the vertical migration patterns. Stations where the highest catches of vertically migrating mysids were obtained during the October cruise were selected for further studies, comprising higher vertical resolution and repeated sampling to reveal the vertical distribution throughout the night. In December, a total of 21 IKMT samples were obtained at Stns 2 and 3. Approximately 1500 to $2000 \mathrm{~m}^{3}$ of water were filtered during each tow. Stn 6 was sampled by means of a large pump (Flygt mixer; Solemdal \& Ellertsen 1984) with capacity ca $14 \mathrm{~m}^{3} \mathrm{~min}^{-1}$. The net of the pump was $333 \mu \mathrm{m}$, and ca $400 \mathrm{~m}^{3}$ were filtered for each sample. In January 1987, Stn 6 was further investigated by IKMT. Twenty-four nocturnal samples were obtained. In addition, 3 hauls (1 oblique from bottom to surface and 2 corresponding to the deepest interval in the nocturnal sampling) were taken in the period around sunset $(15: 44$ to $16: 47 \mathrm{~h}$; sunset at 16:00 $\mathrm{h})$. Approximately 700 to $800 \mathrm{~m}^{3}$ were filtered during each tow.

In the multidisciplinary surveys in Masfjorden, a number of samples were collected using an IKMT with a $2 \mathrm{~mm}$ mesh net towed at 3 knots. These were always checked for the presence of suprabenthic organisms. Sampling data are given by Kaartvedt et al. (1988).

Temperature and salinity was measured by a Neil Brown CTD.

Currents were measured by a RD-VM Acoustic Doppler Current Profiler (ADCP), which employs the acoustic Doppler technique to measure vertical profiles of horizontal water currents from a moving vessel. An integration time of 5 min was used, giving an accuracy of 1 to $2 \mathrm{~cm} \mathrm{~s}^{-1}$ (product specifications). Measurements in the upper 15 to $20 \mathrm{~m}$ have been omitted due to high variability which seemed related to sampling procedure. Measurements closer to the bottom than ca $20 \%$ of total depth were disregarded due to the possibility of interference from backscattering. Current profiles are presented in terms of the length axis of the fjord, except for Stn 6. Because of the topography at this station (where it is not meaningful to define currents in terms of the length axis of the fjord), north-south and east-west components are given.

\section{RESULTS}

\section{Hydrography}

CTD-profiles throughout the fjord were fairly similar, and only one salinity and temperature profile from each of the surveys is presented (Fig. 2). The influence of the sill is clearly demonstrated. On all occasions, the water characteristics below sill depth were homogenous (salinities between 34.8 and $35.0 \%$ and temperatures of 7.3 to $7.5^{\circ} \mathrm{C}$ ). Above sill depth, salinity decreased and temperature increased, leading to a marked pycnocline between the basin water and the intermediate water. The pycnocline was most prominent in October.

\section{Currents}

A great number of current profiles were obtained throughout the fjord, but only a few selected profiles are presented. Subsequent profiles generally revealed the same main pattern, although effects from the varying topography as the boat proceeded influenced the profiles to some degree (see Fig. 6)

In October 1986, the current profiles to a large extent depended on the tidal cycle. An example from Stn 3 is given in Fig. 3. Before high tide, currents

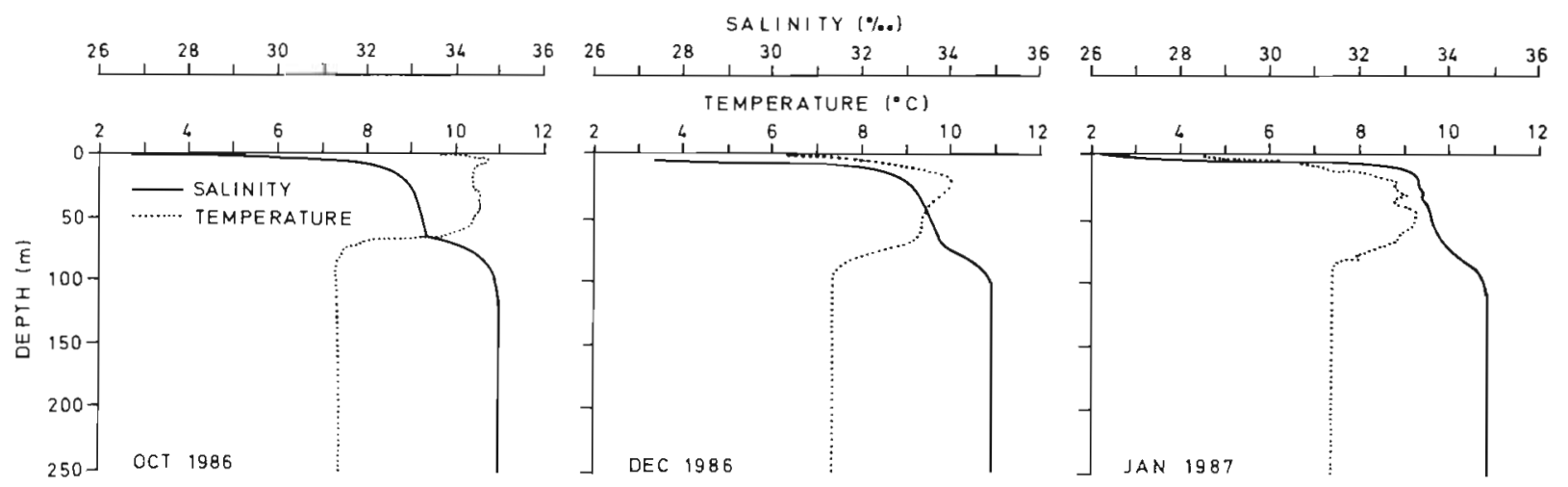

Fig. 2. Vertical temperature and salinity profiles in October and December 1986, and in January 1987 


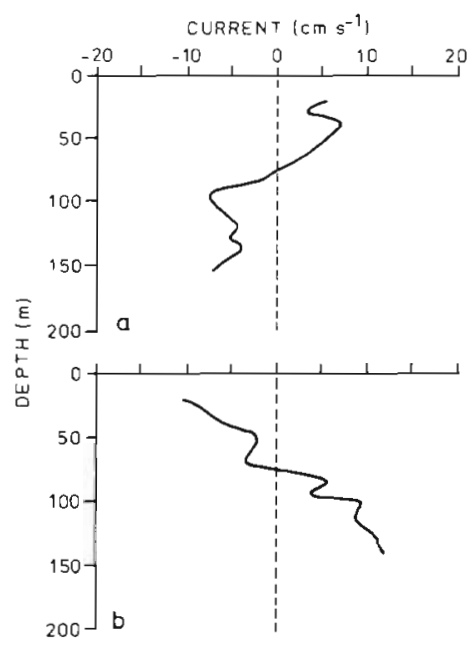

Fig. 3. Current profiles in October 1986. Tidal variations at Stn 3 ; (a) $1 \mathrm{~h}$ prior to high water, (b) $1.5 \mathrm{~h}$ prior to low water Positive values represent ingoing currents

were directed inwards above sill depth and outwards below sill depth. The reverse situation was found prior to ebb tide. Measurements on other dates revealed the same shift in direction with the tidal cycle. The shear-level between in- and outgoing currents was always located approximately at sill depth. Above sill depth, similar patterns in the current profiles were found along the whole main axis of the fjord, except for the head of the fjord (inner part of Stn 2) where velocities were weak throughout the water column (not shown). Maximum

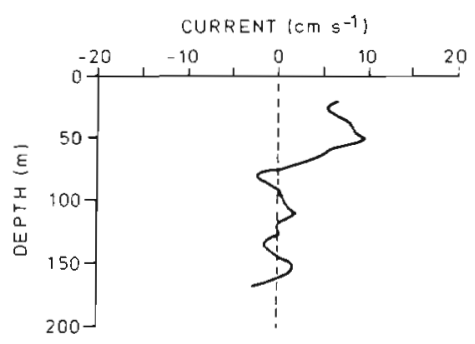

Fig. 4. Current profiles in October 1986. Profile at Stn 10,0.5 h prior to high water. Positive values represent ingoing currents

velocities were 8 to $10 \mathrm{~cm} \mathrm{~s}^{-1}$. Below sill depth, currents were feeble in the outer stns (Fig. 4).

Currents were weak at Stn 6, which may be located in a backwater. Measurements generally varied between undetectable currents to velocities of a few $\mathrm{cm} \mathrm{s}^{-1}$.

In December 1986, the currents in the intermediate layer were stronger than in October, and maximum velocities recorded at Stns 2 and 3 were 15 to $20 \mathrm{~cm} \mathrm{~s}^{-1}$ (Figs. 5 and 6). Velocities below sill depth were lower. Similar profiles (not shown), were revealed in the main basins (Stns 4, 5, and 9). Currents were clearly influenced by the tides (Fig. 5). Periods with strong outgo-

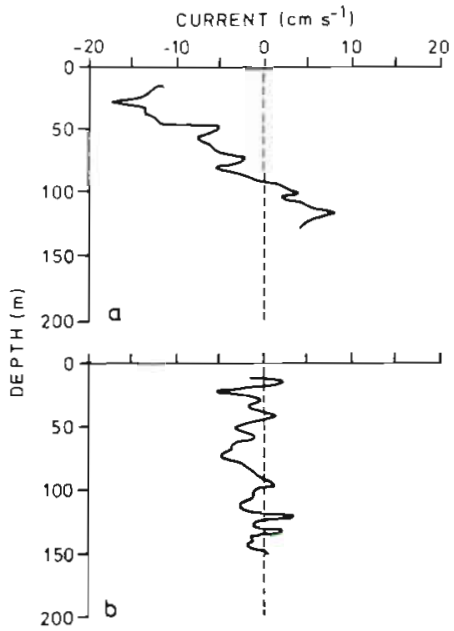

Fig. 5. Current profiles in December 1986. Tidal variations at Stn 3; (a) $0.5 \mathrm{~h}$ following low water, (b) around high water. Positive values represent ingoing currents

ing currents above sill depth were followed by periods with weak and vertically variable currents before the initial pattern was re-established.

As in October, currents diminished towards the head of the fjord. This is illustrated in Fig. 6, where all profiles (except one missing profile) obtained during an IKMT-tow at Stn 2 is presented.

At $\operatorname{Stn} 6$, currents were relatively weak during both flood and ebb. The vertical profiles varied somewhat throughout the measurement period, but velocities did generally not exceed $5 \mathrm{~cm} \mathrm{~s}^{-1}$ in this location. Vertical shear was a prominent feature of the current profiles (Fig. 7).

In January 1987, currents were relatively weak throughout the fjord. Maximum velocities recorded at Stn 6 were $5 \mathrm{~cm} \mathrm{~s}^{-1}$ Vertical shear was a prominent feature of the current profiles.

\section{Distribution of mysids}

\section{Horizontal distribution}

The distribution of mysids along the fjord during the survey in October 1986 is given in Table 1. It appears that the mysids occupied distinct locations during their pelagic phase at night.

Boreomysis megalops was mainly found in the inner part of the fjord at Stns 2 and 3. The species was never caught in the adjacent deep areas (Stns 4 and 5). Catches of B. megalops were also obtained at Stns 8, 9, and 10.

Lophogaster typicus was found in highest concentrations at Stn 6. There was a sharp decrease in abundance towards the adjacent Stns 7 and 8. L. typicus was also present at Stn 10 .

Leptomysis gracilis was mainly restricted to Stn 6 .

Schistomysis ornata was repeatedly found in low 

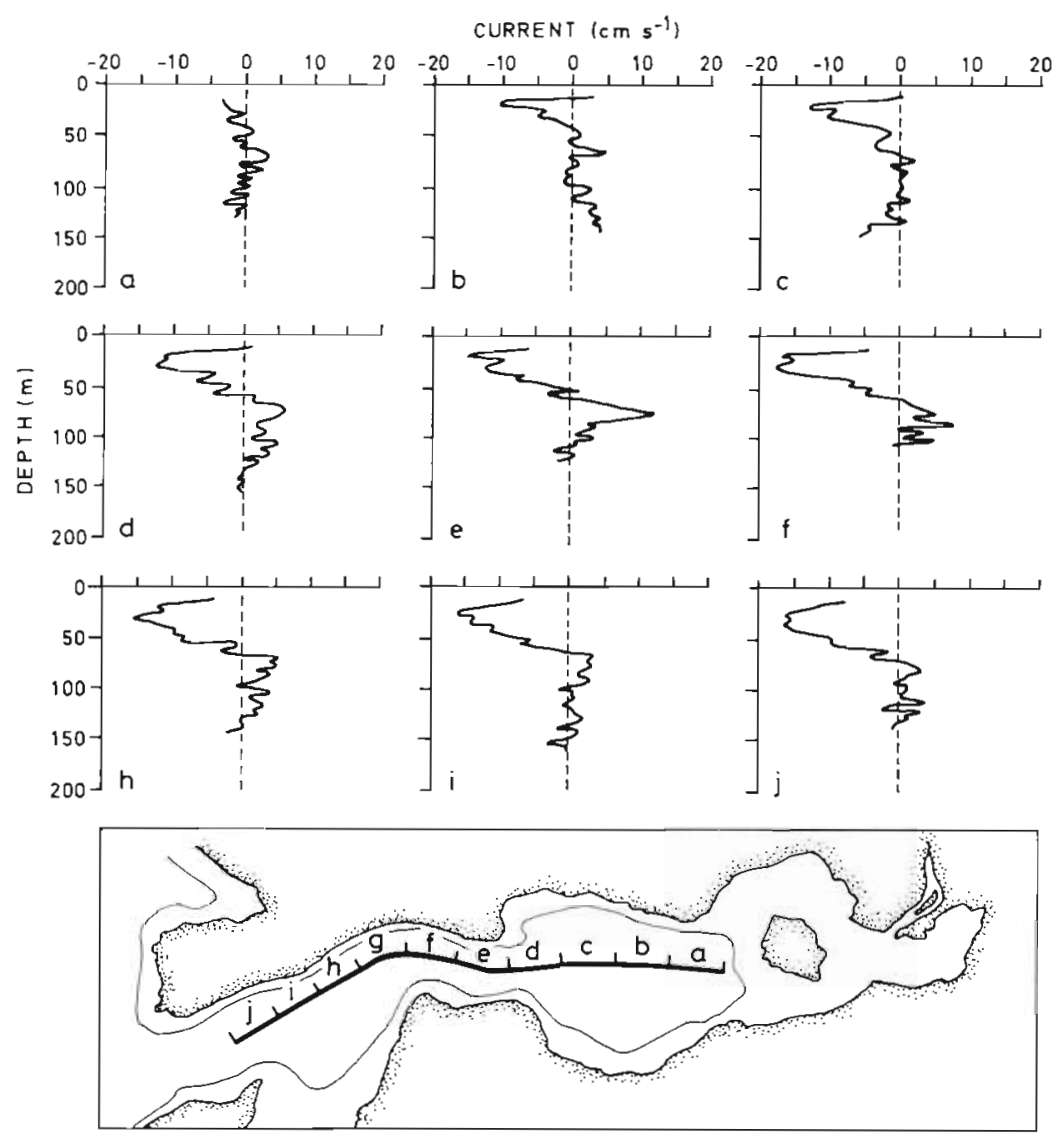

Fig. 6. Current profiles in December 1986. Profiles were obtained during an IKMT tow at Stn 2. Track of the tow together with spatial measurement intervals (ca $300 \mathrm{~m}$ ) of currents are given ( $g$ is missing). Positive values represent ingoing currents

numbers at Stn 1. It was never caught at the adjacent stations in the inner part of the fjord.

\section{Vertical distribution}

Boreomysis megalops. The October sampling gave the largest catches of $B$. megalops in the deepest of the 2 depth strata sampled (Table 1).

Results on the pelagic distribution during night at Stns 2 and 3 in December 1986 are given in Fig. 8. A total of 876 individuals were captured in this sampling. Extensive upwards migration took place, and Boreomysis megalops was found more than $100 \mathrm{~m}$ above bottom. Catches decreased, however, regularly with increasing distance from bottom, and the species was mainly confined to waters below sill depth.

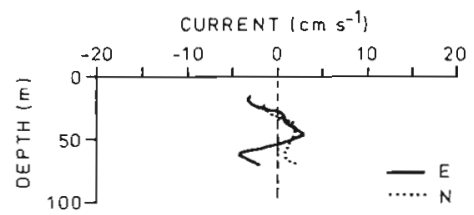

Fig. 7. Current profiles in December 1986. Example of profile at Stn 6. N: north-south component (N positive); E: east-west component (E positive)
Boreomysis megalops lived pelagically throughout the night, although each sample in the corresponding depth intervals gave slightly higher catches in the first of the 2 series. Day and night sampling with the $2 \mathrm{~mm}$ net IKMT at Stn 2 in December 1986 gave no catch in the day compared to 150 individuals at night.

Lophogaster typicus. During the October sampling, the highest catches of L. typicus were obtained in the deepest of the 2 depth strata sampled (Table 1 ).

The pump samples at Stn 6 in December 1986 yielded a total of 248 individuals. In January 1987, 556 individuals were caught during the sampling by the IKMT. Lophogaster typicus was on both occasions distributed throughout the deepest $50 \mathrm{~m}$ of the water column. During ascent from the basin water (their daytime habitat) to the intermediate water, marked salinity and temperature gradients were passed (Fig. 2). Catches generally decreased markedly in the upper $30 \mathrm{~m}$ (Figs. 9 and 10), but occasionally, this mysid was found in the upper $20 \mathrm{~m}$ (Fig. 9).

The results from the pump profiles revealed pelagic activity in all parts of the night. It is, however, indicated that the species was distributed highest in the water colum during the second series (mid-part of the night). The 'replicated' samples in the last series show examples of both high and low replicability. This may be due 


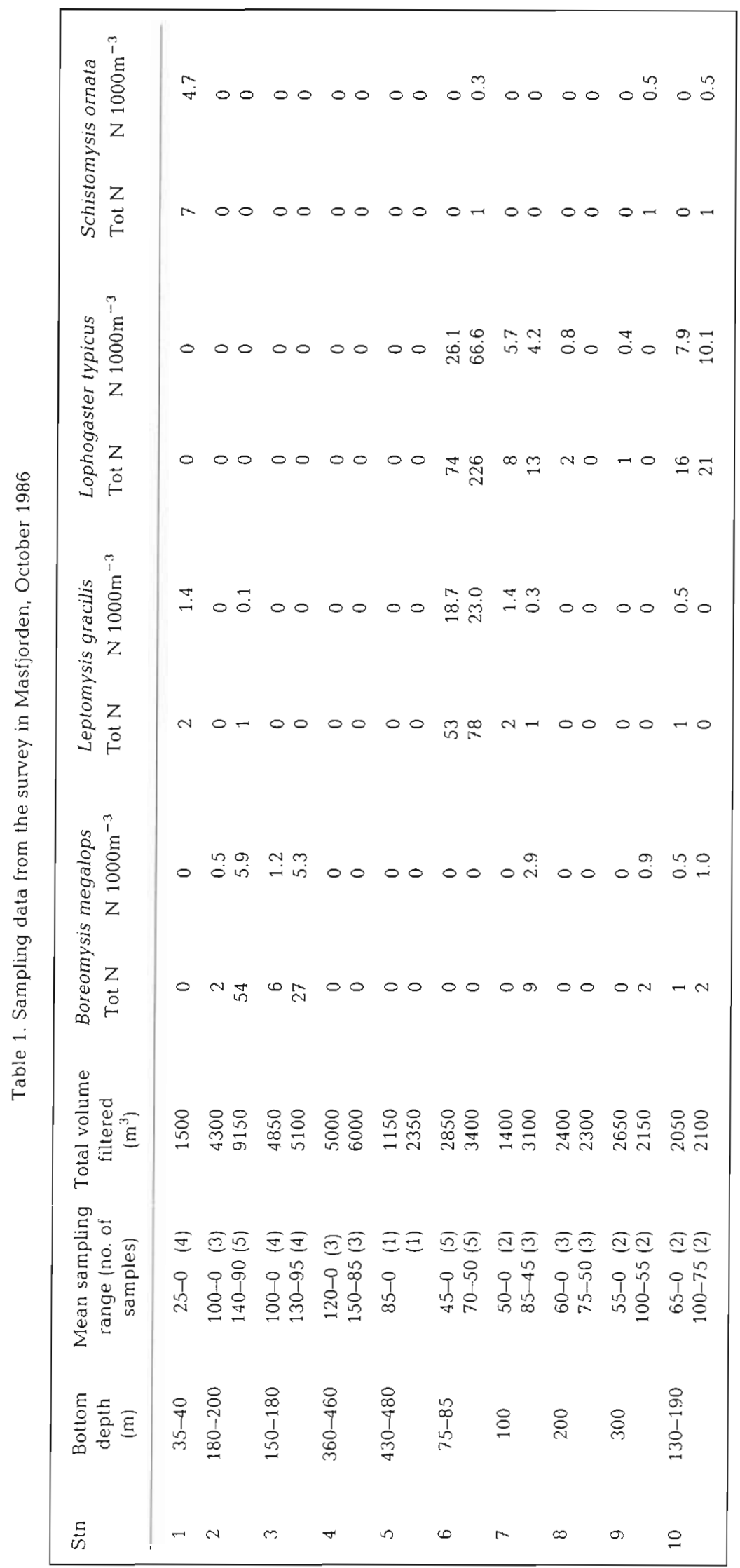




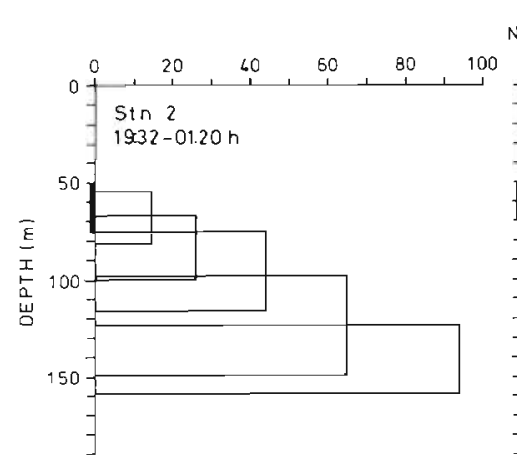

NUMBER OF INDIVIDUALS $1000 \mathrm{~m}^{-3}$
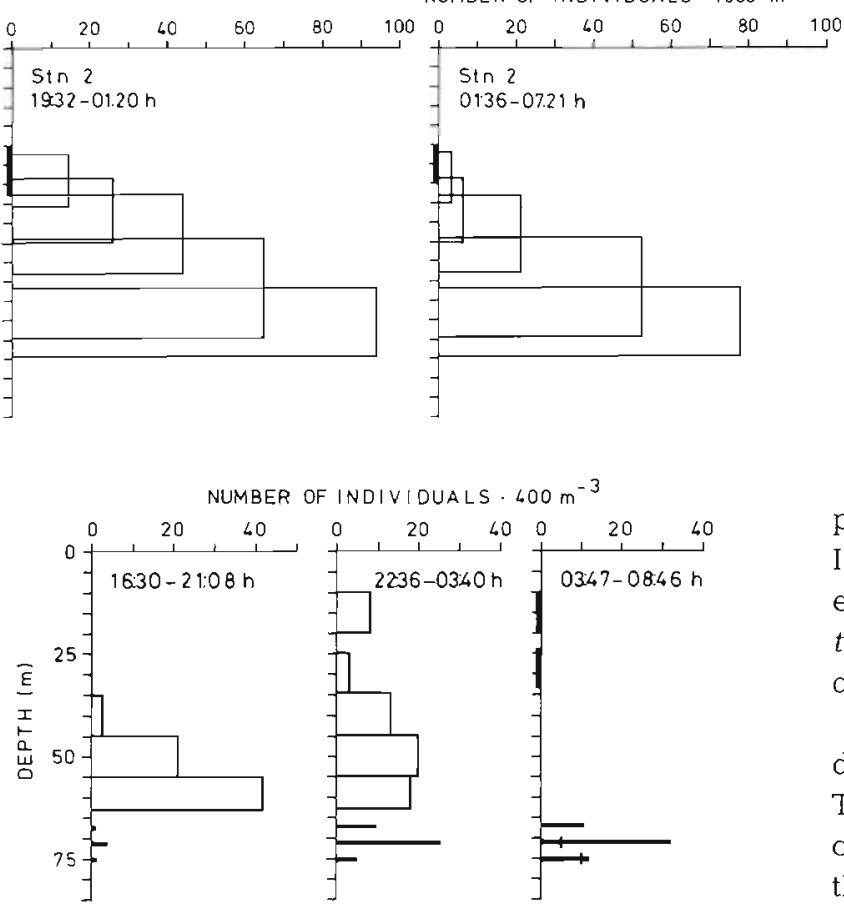

Fig. 9. Lophogaster typicus. Nocturnal vertical distributions at Stn 6 in December 1986 (pump samples). Black bars along the $Y$-axis represent samples with no catch. Perpendicular lines indicate numbers in lower of 2 samples. Bottom depth at pump station is ca 80 to $85 \mathrm{~m}$. Sunset at 15:35 h, sunrise at 09:25 h

to random sampling effects, but may also be caused by the extended time interval within a sampling series. The low catch at $75 \mathrm{~m}$ depth was obtained early in the sampling period $(04: 27$ to $04: 55 \mathrm{~h})$, while the high catch was obtained late in the sampling period (07:35 to 08:05 h). During the IKMT sampling in January 1987, L. typicus was present pelagically throughout the nocturnal sampling period (Fig. 10).

Lophogaster typicus was generally not caught in the water column during day. In December, pumping $10 \mathrm{~m}$ above bottom ca $1 \mathrm{~h}$ prior to sunset gave no catches of L. typicus. In January, only one individual was captured in the 3 IKMT tows close to sunset.

Leptomysis gracilis. In October, L. gracilis was rather evenly distributed between the deep and shallow depth strata (Table 1).
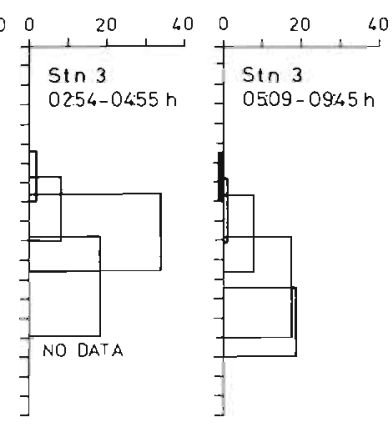

Fig. 8. Boreomysis megalops Nocturnal vertical distributions at Stns 2 and 3 in December 1986 (IKMT samples) Black bars along the $Y$-axis represent tows with no catch. Bottom depth at $\operatorname{Stn} 2$ is ca $190 \mathrm{~m}$, at $\operatorname{Stn} 3 \mathrm{ca} 150$ to $180 \mathrm{~m}$. Sunset at 15:35 h, sunrise at $09: 25 \mathrm{~h}$

This species was not caught to any extent in the pump during the December sampling. An oblique IKMT haul from the bottom to surface gave, however, equal numbers of Leptomysis gracilis and Lophogaster typicus, confirming pelagic activity of $L$. gracilis on this occasion also

In January, the highest catches were obtained in the deepest strata during the first part of the night (Fig. 11). The vertical distribution seemed to change in the course of the night. Catches decreased from the first to the second series in each depth interval. Only small catches were obtained at any depth during the last 2 series. A total of 88 individuals were captured during this sampling. No individuals were captured in the 3 IKMT samples around sunset.

\section{DISCUSSION}

The horizontal pelagic distribution of mysids in Masfjorden was highly patchy (Table 1), and reflected the daytime habitats at the bottom as established by epibenthic sledge sampling (Fosså et al, unpubl.). Only a few indications of transport away from daytime habitats were found. These were 2 individuals of Lophogaster typicus caught at Stn 8 and 1 at Stn 9 (in both cases (rom the upper depth interval sampled) and single individuals of Schistomysis ornata at Stns 9 and 10 (which have no bottom population of this species; Fosså et al. unpubl.).

Results from other surveys in Masfjorden are consistent with the present findings. In the investigation of

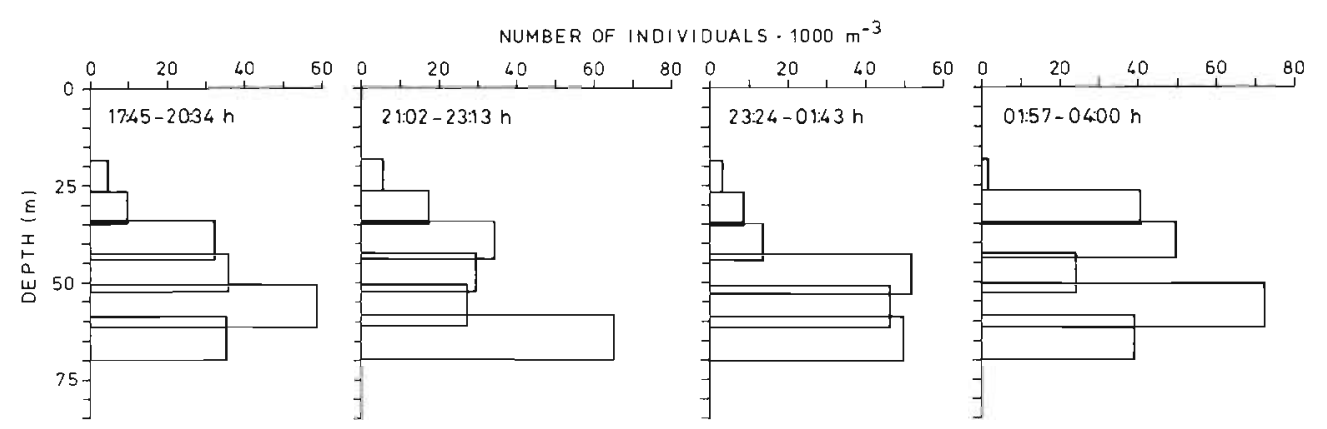

Fig. 10. Lophogaster typicus. Nocturnal vertical distributions at $\operatorname{Stn} 6$ in January 1987 (IKMT samples). Bottom depth is ca 70 to $90 \mathrm{~m}$. Sunset at 16:00 h. sunrise at 09:35 h 


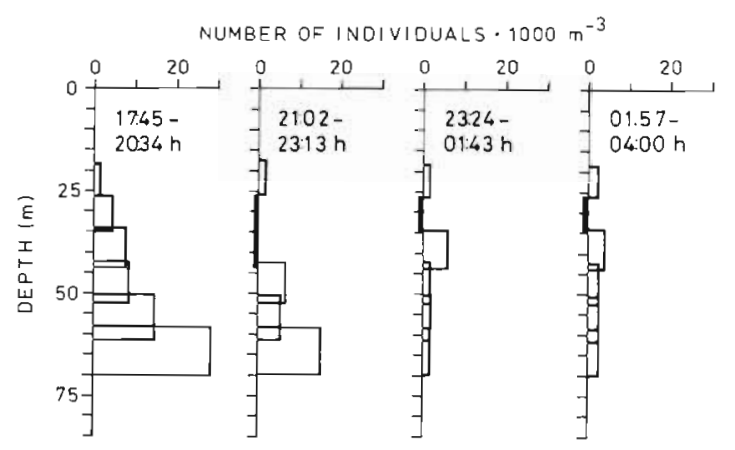

Fig. 11. Leptomysis gracilis. Nocturnal vertical distributions at Stn 6 in January 1987 (IKMT samples). Black bars along the Y-axis represent tows with no catch. Bottom depth is ca 70 to $90 \mathrm{~m}$. Sunset at 16:00 h, sunrise at 09:35 h

Kaartvedt et al. (1988), suprabenthic mysids were repeatedly caught above their known bottom daytime habitats (unpubl.), while dispersal was shown on one occasion only from extensive sampling in the deep basins. Two individuals of Boreomysis megalops, probably transported from their inner, shallower habitat, were then caught in the upper $100 \mathrm{~m}$ at Stn 4 shortly after sunrise.

Both present and previous investigations (Kaartvedt et al. 1988, Aksnes et al. 1989) have demonstrated prominent exchange processes above sill depth in Masfjorden. The presence of a sill, however, enhances retention of deep-living fjord populations. The December results illustrate that Boreomysis megalops, by being confined to the basin water (Fig. 8), encountered relatively weak inwards-directed, or vertically variable, currents (Figs, 5 and 6). Retention of mysids may also be facilitated in locations above sill depth where currents proved to be relatively weak, e.g. at the head and at $\operatorname{Stn} 6$. Large populations of Lophogaster typicus and Leptomysis gracilis indeed persist at Stn 6 (present study, Fosså et al. unpubl.), and the shallow-living Schistomysis ornata was found at the head. L. typicus was, however, also present at Stn 10 (but less abundant than at Stn 6) which is located in the main exchange route for water in and out of Masfjorden. Although $L$. typicus at this station partly spent the night in the low advective basin water (Table 1; Fig. 4), fairly high numbers did enter the upper advective layers where the species was found in currents of 5 to $10 \mathrm{~cm} \mathrm{~s}^{-1}$. Small sledge catches indicate bottom populations at this location (Fosså et al. unpubl.).

Population maintenance in geographic space depends on balance between gain and loss on the time scale of a life cycle. Using certain assumptions, it is possible to quantify what advective loss may be sustained by reproductive rates. For populations living in habitats bordered by uninhabited regions, advection represents a potential loss from the population.

Corresponding to Ketchum (1954), the daily instan- taneous advective loss ( $\lambda$ ) may be expressed as (Kaartvedt 1988):

$$
\lambda=-\ln (1-\mathrm{F})
$$

where $F=$ daily fraction of the population lost due to water renewal. Provided that advection only takes place during vertical migration at night, $F$ may be expressed as:

$$
F=N_{m} C T / N L
$$

where $N_{m}$ = number of vertically migrating individuals; $N=$ population size; $\mathrm{T}=$ time spent in the pelagic domain (fraction of $24 \mathrm{~h}$ ); $\mathrm{C}=$ mean current velocity during time span $\mathrm{T}_{i} \mathrm{~L}=$ habitat size.

Lophogaster typicus at $\operatorname{Stn} 6$ is chosen as an example. There is no population at the boundary (Table 1), which means that advection only represents loss. The species is known to burrow into the sediment during daylight (Macquart-Moulin 1973, Bjerkestrand 1979, Fosså 1986), thus vulnerability to advection is restricted to the pelagic phase at night. The entire population takes part in vertical migration (Kaartvedt 1985, Fosså et al. unpubl.) giving $\mathrm{N}_{\mathrm{m}} / \mathrm{N}=1$. The length of the habitat (L) is set at $1000 \mathrm{~m}$. The pelagic phase lasts all night (Kaartvedt 1985, present investigation), and is as an annual mean conservatively set to $10 \mathrm{~h}(\mathrm{~T}=10 / 24)$.

Lophogaster typicus lives for up to $1 \mathrm{yr}$ in western Norwegian fjords. The mysid does not spawn more than twice during its lifetime, and average numbers of progenies per batch are about 30 (Bjerkestrand 1979). Setting the sex ratio at $1: 1$ (Bjerkestrand 1979) and the generation time to $180 \mathrm{~d}$, this corresponds to a maximum birth rate (b) of $0.015 \mathrm{~d}^{-1}$ (Paloheimo 1974).

The value of $b$ can be substituted for $\lambda$ in Eq. (1), which then represents the steady state with fecundity counteracting advective loss. If Eq. (1) is substituted into Eq. (2), the only remaining unknown parameter is the current velocity $C$. It can then be estimated that the fecundity of Lophogaster typicus at best could sustain a loss corresponding to a transport of $0.04 \mathrm{~cm} \mathrm{~s}^{-1}$. From equivalent calculations it appears that at a residual current of $0.5 \mathrm{~cm} \mathrm{~s}^{-1}$, a birth rate of 0.198 females $\mathrm{d}^{-1}$, corresponding to ca $3 \times 10^{15}$ female offspring per batch, would be required to compensate for advective loss, assuming the mysids are passively displaced.

In these calculations, mortality is disregarded, and the possibilities of emigration and immigration (mysids are known to perform horizontal migrations; Tattersall \& Tattersall 1951, Mauchline 1980) have been neglected. The argument also relies on certain assumptions, and the possibility of maintenance within an area by drift in gyres is not accounted for. Nevertheless, the calculations indicate that population maintenance is virtually impossible if mysids are drifting passively even at very low advective rates. This suggests that 
severe selection pressure exists for the development of appropriate behaviour to enhance retention. Also the potential impact of the physical setting (habitat size, current velocities) is suggested. The outcome of the calculations is very sensitive to the values of the parameters determining $F$ (Eq. 2). By reducing any of the parameters $\mathrm{N}_{\mathrm{m}} / \mathrm{N}$ (fraction of population taking part in vertical migration), $\mathrm{T}$ (time spent pelagically), or $\mathrm{C}$ (current velocity) to $10 \%$ of the values above, or increasing $L$ (habitat size) correspondingly, the number of offspring per batch required to compensate for advective loss is reduced from $3 \times 10^{15}$ to 25 .

In both Lophogaster typicus and Leptomysis gracilis, the entire population seems to leave the bottom at night and remain in the pelagic phase through the dark period (Kaartvedt 1985). On the other hand, part of the population of Boreomysis megalops may remain in the suprabenthic region at night (Kaartvedt 1985), and in Masfjorden large numbers have been caught by epibenthic sledge at night (Fosså et al. unpubl.). In the present study, pelagic catches were much higher in December than in October. This apparently relates to behaviour, and not abundance, as suprabenthic catches in daylight on these occasions did not vary accordingly (Fosså et al. unpubl.). In fact, daytime sampling by sledge at Stn 3 during the October cruise revealed the highest number of $B$. megalops ever found in the fjord. By reference to the above calculations, such flexibility in the migration pattern may contribute markedly to retention if the tendency to migrate is reduced during periods of strong currents. With the reservation that the strong currents recorded in the basin water at the main habitat of $B$. megalops in October (Fig. 3) are not representative for the entire biological sampling period, the reduced tendency to migrate in October is in acordance with this argument. Perry \& Neilson (1988) found that the suprabenthic mysid Neomysis americana was most abundant in the water column during periods with minima in tidal current speed.

Previous sampling by epibenthic sledge in a western Norwegian fjord has shown that Boreomysis megalops at times return to deeper layers while it is still dark (Kaartvedt 1985). A gradual return to deeper layers is also a possible interpretation of the pelagic distributional pattern found in Leptomysis gracilis at Stn 6 in January 1987. This implies that the exposure time in the free water masses is reduced, which, according to the calculations above, may have large impact on advective loss. Furthermore, through gradual changes in vertical distribution the migrating individuals may interact with currents of opposite directions, thereby enhancing retention. The pump profiles at Stn 6 in December 1986 indicate that Lophogaster typicus also may change its vertical distribution throughout the night (Fig. 9). In this respect, it is noteworthy that vertical shear in the current profiles was a prominent feature at Stn 6 in both December 1986 and January 1987.

The distributional patterns observed during the surveys in Masfjorden are snapshots from periods shorter than the biological time scales of interest. Persistence of permanent populations requires that the species must cope with the variations of events integrated over a life cycle, including for example deep-water renewals. Fosså (1985) found evidence of advection of suprabenthic mysids associated with deep-water renewals in Hauglandsosen, western Norway. Nevertheless, Boreomysis megalops for example, was numerous throughout the year, and the fluctuations accompanying deep-water renewals were in this species on the same order of magnitude as those in mysids which do not undertake diel vertical migrations. On the other hand, extensive sampling by sledge in fjords, in the Norwegian Trench and on the continental shelf where currents are stronger than in the fjords (e.g. Aure \& Sæetre 1981) has revealed that vertically migrating mysids are not abundant at the shelf and trench locations. In contrast, fjord-living species which do not undertake extensive vertical migrations also have abundant populations in these more advective environments ( $\mathrm{T}$. Brattegard pers. comm.).

To conclude, advection is potentially an important factor in population regulation of vertically migrating suprabenthic mysids. Fjords offer suitable habitats by reduced advective forcing. Nonetheless, current velocities are sufficiently high to advect mysids away from their habitats (which may be of very restricted geographic extent) if passively dispersed. Such displacement is, however, not prominent, and thus mysid behaviour seems to enhance retention.

Acknowledgements. D. Aksnes, T Brattegard, J. H. Fosså, and $T$. Hoisæter gave valuable suggestions for improvements of the manuscript. Figures were drawn by Elin Holm. I am grateful to the captain and crew of RV 'Håkon Mosby' for their cooperation and assistance.

\section{LITERATURE CITED}

Aksnes, D. L., Aure, J., Kaartvedt, S., Magnesen, T., Richard, J. (1989). Significance of advection for the carrying capacities of fjord populations. Mar. Ecol. Prog. Ser. 50: 263-274

Aure, J., Sæatre, R. (1981). Wind effects on the Skagerak outflow. In: Sætre, R., Mork, M. (eds). The Norwegian Coastal Current. University of Bergen, p. 263-293

Bjerkestrand, B. I. (1979). Lophogaster typicus. (M. Sars) (Crustacea, Mysidacea) i Fanafjorden. Reproduksjon, vekst og energiinnhold. Thesis, Univ. of Bergen

Brunel, P. (1979). Seasonal changes in daily vertical migrations in a suprabenthic coldlayer shelf community over 
mud in the Gulf of St. Lawrence, In: Naylor, E., Hartnoll R. G. (eds). Cyclic phenomena in marine plants and animals. Proc. 13th Europ. Mar Biol. Symp. Pergamon Press, Oxford, p. 383-390

Clutter, R. I. (1969). The microdistribution and social behaviour of some pelagic mysid shrimps. J. exp. mar. Biol. Ecol. 3: 125-155

Fosså, J. H. (1985). Near-bottom vertical zonation during daytime of deep-living hyperbenthic mysids (Crustacea: Mysidacea). Sarsia 70: 297-307

Fosså, J. H. (1986). Aquarium observation on vertical zonation and bottom relationships of some deep-living hyperbenthic mysids (Crustacea:Mysidacea). Ophelia 25: 107-117

Hahn, P., Itzkowitz, M. (1986). Site preference and homing behaviour in the mysid shrimp Mysidium gracile (Dana). Crustaceana 51: 215-219

Hollister, C. C., Nowell, A. R. M., Jumars, P. A. (1984). The dynamic abyss. Scient. Am. 250 (3): 32-43

Jahn, A. E., Lavenberg, R. J. (1986). Fine-scale distribution of nearshore, suprabenthic fish larvae. Mar Ecol. Prog. Ser 31: 223-231

Kaartvedt, S. (1985). Diel changes in small-scale vertical distribution of hyperbenthic mysids. Sarsia 70: 287-295

Kaartvedt, S. (1988). Significance of vertical migrations for advection and retention of fjord-living crustaceans. Doctoral thesis, Univ. of Bergen, Norway

Kaartvedt, S., Aksnes, D., Aadnesen, A. (1988). Winter distribution of macroplankton and micronekton in Masfjorden, western Norway. Mar. Ecol. Prog. Ser. 45: 45-55

Ketchum, B. H. (1954). Relation between circulation and planktonic populations in estuaries. Ecology 35: 191-200

Mauchline, J. (1980). The biology of mysids and euphausiids Adv. mar. Biol. 18: 1-681

This article was submitted to the editor
Macquart-Moulin, C. (1973). L'activité natatoire rytmique chez les péracarides bentho-planctoniques. Detérminisme endogène des rythmes nycthemeraux. Tethys 5: 209-231

McFarland, W N., Kotchian, N. M. (1982). Interaction between schools of fish and mysids. Behav. Ecol. Sociobiol. 11: $71-76$

Orsi, J. J. (1986). Interaction between diel vertical migration of a mysidacean shrimp and two-layered estuarine flow. Hydrobiologia 137: 79-86

Paloheimo, J. E. (1974). Calculation of instantaneous birth rate. Limnol. Oceanogr. 19: 692-694

Perry, R. I., Neilson, J. D. (1988). Vertical distribution and trophic interactions of age-O Atlantic cod and haddock in mixed waters of Georges Bank. Mar. Ecol. Prog. Ser 49: $199-214$

Robertson, A., Power, C. F., Anderson, R. F. (1968). Direct observation on Mysis relicta from a submarine. Limnol. Oceanogr. 13: 700-702

Solemdal, P., Ellertsen, B. (1984). Sampling fish larvae with large pumps; quantitative and qualitative comparisons with traditional gear. Flødevigen rapportser 1:335-363

Sætre, R. (1974). En hydrografisk undersøkelse i Matrevăgen, Nordhordland. Fisken Hav. (ser. B) 1974 (6). 68 pp. (Norwegian)

Tattersall, W. M., Tattersall, O. S. (1951). The British Mysidacea. Ray Society, London

Wittmann, K. J. (1977). Modification of association and swarming in North Adriatic Mysidacea in relation to habitat and interacting species. In: Keegan, B. K., Céidigh, P. O., Boaden, P. J. S. (eds.) Biology of benthic organisms. Pergamon press, Oxford, p. 605-612

Wooldridge, T., Erasmus, T (1980). Utilization of tidal currents by estuarine zooplankton. Estuar. cstl Shelf. Sci 11: 107-114

Manuscript first received: November 8,1988

Revised version accepted: June 27, 1989 